This item was submitted to Loughborough's Research Repository by the author.

Items in Figshare are protected by copyright, with all rights reserved, unless otherwise indicated.

\title{
The hieroglyphic other: The Beetle, London and the anxieties of late Imperial
}

\section{England}

PLEASE CITE THE PUBLISHED VERSION

http://www.palgrave.com/products/title.aspx?PID=276489

PUBLISHER

(C) Palgrave Macmillan

VERSION

AM (Accepted Manuscript)

LICENCE

CC BY-NC-ND 4.0

\section{REPOSITORY RECORD}

Wolfreys, Julian. 2019. "The Hieroglyphic Other: The Beetle, London and the Anxieties of Late Imperial England”. figshare. https://hdl.handle.net/2134/8596. 
This item was submitted to Loughborough's Institutional Repository (https://dspace.lboro.ac.uk/) by the author and is made available under the following Creative Commons Licence conditions.

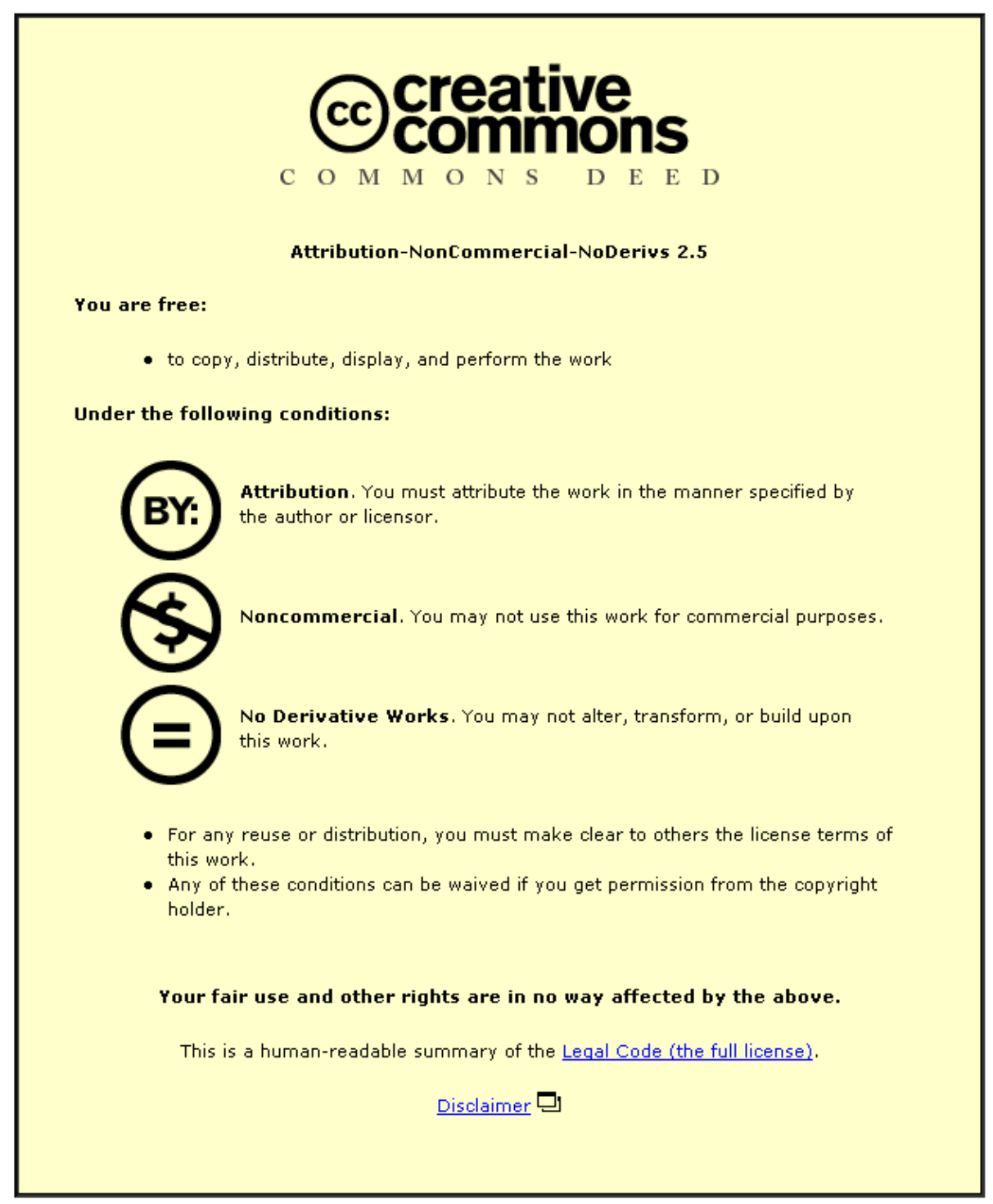

For the full text of this licence, please go to: http://creativecommons.org/licenses/by-nc-nd/2.5/ 
The Hieroglyphic Other: The Beetle, London, and the Anxieties of Late Imperial England

...what a monster must London be, extending (to take it in a line) from the farther end of Chelsea, west, to Deptford-Bridge east, which I venture to say, is at least eleven miles.

Daniel Defoe

A modern suburb is a place which is neither one thing nor the other.

Anon., 1876

I

In this, the first chapter of Writing London: Inventions of the Other City, I wish to propose what might appear at first an untenable hypothesis. From that, and concomitantly projected, I intend to describe and so situate an equally improbable, not to say foolhardy, analogy. Put as directly as possible, it is this: in both the formal composition of the Richard Marsh's most successful novel The Beetle, and in the creation of the creature 'born of neither god nor man' for whom this fin de siècle Gothic narrative of the consequences and crisis of empire is named, there are to be discerned peculiar and singular structures and cultural interactions. The encounter with such assumed formal relationships foreground and illuminate that which is occluded or obtusely present in particular urban identities. In their singularity, such forms stage pastiches of specific cultural ontologies analogous with the perception of London at the end of the nineteenth century.

They thus present the reader with an inscription of historical, cultural and ideological anxiety as a dissonant constitutional component at the empire's heart, its capital, as well as in those who represent its typical upper and middle class types. The complex or pattern of implied normative social relations is opened at a moment of crisis in order to unveil to the reader that 
which is projected as necessarily grotesque and other within the intercommunications and privileged discourses of the subjects who inform and maintain an otherwise hegemonic grid on which the social order is maintained. This perceived, necessary monstrosity and the accompanying radical undecidability that, in turn, underlies the provisional determination of London as monstrous at the fin de siècle finds its most exemplary and yet troubling figure, as I wish to argue, in Richard Marsh’s ‘liminal man-woman-goddess-beetle-Thing’ (Luckhurst 2000, 160). More than merely a figure, the Beetle in its protean transformability that worries at the very definitions of gender and sexuality is, and must be read as, effectively, a trope that resists mastery or control. Moving through the city and a few of its inhabitants' lives and imaginations, it inscribes a countersignature to London, thereby intimating those uncontrollable forces that are the city's own. The Beetle does not merely rewrite the city. Neither does he / she / it simply make urban space complicit in the staging of transgressive acts. In Marsh's imaginatively constructed night world, London is locus and agent, as well as provisional identity for monstrous otherness.

In that Marsh chooses recognizable fictional types drawn from popular literary genres, he produces and writes the city's late nineteenth-century culture through a few paradigmatic stereotypes, which are, themselves, phatic snapshots of that culture. Into this cultural demimonde, comes this other hieroglyphic 'text', the Beetle. Far from being just some identifiable 'Oriental other' however, the Beetle implicates itself into a network of discourses in fiction and culture. In this, it provides the opportunity for Marsh to construct a number of interwoven pastiche narratives of gender, class, institutional and oppositional politics, science, technology, and the economic and ideological bases on which the city thrives. To stress this point again from the outset, such a discursive matrix has less to do with the foreign as such than with the limits of 
any ontological and ideological programme of definition aimed at self-fashioning. In its radically abyssal and archaic heterogeneity therefore, and through its motions and interactions with the fictional and cultural 'types', whose very narratives are themselves stereotypical vignettes, the Beetle serves to focus once again, the fears expressed in much fin de siècle literature, whilst also revealing that within the narratives and discourses which is other to them. At the same time, Marsh's bizarre and fantastic, powerful being also draws attention to particular currents in the popular culture and psyche of Late Victorian London, by which the late imperial city comes to be aligned with the moral corruption, decay, and degeneracy of its fictionalized 'underworld'.

While the creature we call the Beetle has within the novel a signifying materiality intimating radical alterity and ontological instability, it is only the most extreme manifestation of the novel's destabilizing forces therefore. As I have already proposed, there are those aspects of Marsh's novel in its formal condition, its contours and trajectories that attain to and signal a fluctuating otherness. In this, the novel itself is excessive beyond hybridity or polyvocal play. It presents through its narrative how that series of pastiche first-person tales neither have ground nor centre. Presented sequentially, the narratives' competing claims deny the possibility of a consensual centre given material manifestation as the city as the heart of empire. This dismantling of the assumption of a 'heart' or 'core' undoes any privileged meaning for London thereby demonstrating its own monstrous and mutable state. In this, London is therefore akin to the Beetle in its resistance to a final ontologization. Being haunted by numerous traces of successive states of abjection and otherness from within itself, and moving its narrative along through the frequent display of supplementary statements that offer a critique, directly or otherwise, of the very premises of any stable meaning or identity, both The Beetle and the Beetle, place alterity, abjection and a vertiginous abyss as the axial khoric focal point of all 
determination. Through this strategy, London is understood to be available therefore only as an ever-changeable site of fluctuating and variable forms, each of which find or invent the city they require in order to sustain particular boundaries of selfhood.

The novel, the creature, the city: a triad then, each the duplication and other of each other, and yet singularly other to each other, because of their alterity. We are dealing here with the triplication of a Borromean knot, so lacking in a centre and so intent on erasing the very possibility of a fixed core that their mirroring functions as an 'apparatus of disclosure' (Armand 2006, 51). This apparatus that describes and functions through constantly shifting internal differences 'screens, mediates, translates, interprets and metaphorises' (Armand 2006, 51) in order to unveil a 'deformation irreducible to any form', as Derrida puts it in Dissemination (314). And this, with London as the mise en scene for such activity, underwrites its own ghastly spectralization. Marsh's tripartite apparatus—a catachresis machine perhaps— 'describes a structural matrix, a mechanism or programme in which the ghost writing of the signifier [but which one, precisely?] in the illusion of a signified marks a schematics' (Armand 2006, 51) of 'a lost memory of what is no longer here' (Derrida 1992b, 31.3). The Beetle’s revenant eruption is just the appalling 'memory' of the impossibility of origin, or that, apropos of London, this too has been one of the dark places of the earth. Cultural consciousness in the narrative is so caught up in the illusion of itself under threat, a threat to self which it misreads as a threat to the illusion of centre and origin, that it cannot read. It cannot read; it either fails or avoids reading either its own 'confusion of arche and mimesis' (Armand 2006, 52) or the Beetle and the otherness of the city as 'ghosts in the machine'. The spectral excess thus presents urban identity as always other to itself. This is the very meaning, we might say, of a being-there which just is being-in-London, all the elements, signifiers, and traits of which are part of what Hélène Cixous calls a 
'metonymic chain where the other place always has its other place' (1984, 23). Marsh realizes, more than any of his contemporaries perhaps, that London 'gives' itself as the name of a being of which there is no being, as the name for that which is beyond being or presence.

In order to pursue such monstrous analogy, one in which relation fragments rather than making connection, I shall turn first to Marsh's novel and his creature as the provisional embodiment of late imperial phobias I have sketched, before offering an analysis of mapping and representation of London in The Beetle. I do so in order to pursue, and so outline, the multiple overdeterminations of the text, addressing in this manner the particular cultural discourses of The Beetle as these together offer a sense of productive disorder that confounds ontology and foregrounds otherness. The Beetle arrives therefore, as if it were some 'illegal' immigrant, its 'illicitness' proposed by others the very device that exposes the competing striations and their points of stress and fracture within the illusion of a 'present' identity produced only by the contesting claims of its inhabitants’ desires.

II

Published in September 1897 just two months after Dracula, The Beetle is a novel in which the various facets of late-Victorian modernity, science, parliamentary democracy, imperial identity, and, most generally expressed, the nineteenth-century investment in the attainability and efficacy of knowledge as a form of power and control are confronted by the non-rational, the inexplicable, the archaic, the other. Taking place in fin de siècle London, and almost entirely at night, it brings together the dominant fears and anxieties of the age, as it confronts through its narrative various dissolutions of personal and cultural identity. It thus exemplifies 'the post- 
Darwinian imperial age that is the late nineteenth century', as Daniel Bivona has it, in which “"knowledge” of the alien Other is being produced on a large scale, and occasioning a crisis in the way England looks at itself' (1990, 75). As Bivona implies and as is now largely accepted, this alterity is never in any simple fashion external to Englishness. It erupts in numerous places from within that national identity. Moreover, it is arguable that such potentially ruinous fragmentation of identity comes to haunt the very form of the novel itself. The extent to which such a haunting takes place for the reader at the fin de siècle is all the more pronounced when something such as the Beetle which is so undeniably archaic, and capable of shape-shifting, is able to move with apparent ease, not only throughout the streets of London, but to enter its houses and homes. But to pause for a moment: beyond the obvious internal narrative logic that accepts supernaturalism as its necessary premise, what are the conditions by which Marsh's creature is able to produce such disruption?

We might begin by locating such disturbances in the novel's use of mesmerism, the practice of which was widespread throughout the nineteenth century. If we recall briefly many fin de siècle London-texts, such as Dorian Gray, The Strange Case of Dr Jekyll and Mr Hyde, any of the Sherlock Holmes tales, or even later texts such as The Secret Agent or The Lodger, the 'city of dreadful night' as it was widely understood undoubtedly provides an exemplary site for the hallucinatory and phantasmagoric. One might even venture to suggest that the night world of London offers for the writer endless possibilities for what I wish to define provisionally as the 'mesmeric' text.

As Alison Winter puts it, 'Mesmerism was not only ubiquitous but a challenge and threat within Victorian intellectual culture, as experiments became catalysts for competing assertions about the nature and seat of intellectual authority' $(1998,5)$. While in Jekyll and Hyde, chemistry 
provides the narrative 'trick' for dividing identity, in The Beetle it is mesmerism. As Robert Holt reflects in his narrative, under the Beetle's hypnotic power, “"My condition was one of dual personality”' ( $B$ 69). While being put to legitimate medical uses from the late eighteenth century, mesmerism quickly acquired the patina of a sideshow entertainment, or otherwise suggested nonrational, non-European mysticism. Winter rightly remarks of mesmerism, that, from the 1870s onwards, it 'became the occasion for self-conscious reflections about the basis of race inequalities and the natural laws that helped one people to bend another to its will' (B 7). What is truly unsettling, I would suggest, for the late Victorian reader of The Beetle, is that a 'science' is appropriated by a non-European monstrous other. The Beetle calls into question 'legitimate' or more benevolent applications of mesmerism, familiar in the period, for clearly criminal and sexual purposes. Yet it should be noted in passing, this 'aberration' concerning the 'proper' uses of science implicitly anticipates another element in the narrative, one which is closer to home, practiced in someone's home to be precise. For by its deployment of mesmerism as part of its apparatus of disclosure, The Beetle demands we reflect on the uses of science in the name of the country, through the production of what are now called weapons of mass destruction, which is touched on in the work of the amateur, gentleman scientist of the novel, Sydney Atherton. Atherton invents and constructs deadly weapons for the government to be used overseas in a laboratory in his upper-class home. Here we have a powerful blind-spot within the narrative in which the reader is invited at least to consider what goes on in the homes of the ruling classes.

Indeed, Atherton's 'improper' use of his house, his secret practice and understanding of the hieratic discourse of science, particularly its 'darker' uses, serves economically to highlight how none of the houses in the novel are homely, all are transgressed in some manner, and not just by the Beetle. Paul Lessingham's house is the structural site for the return of the repressed in 
the form of his own alleged foreign transgressions and the minor 'breakdown' he suffers as a result of its being brought to light. Marjorie repeatedly disobeys the Law of the Father in the Father's house, and Holt breaks into an unoccupied home. The only 'house' put to its 'proper' use, conventionally understood is the House of Commons. Or, looking at this from another perspective, the one already introduced, Marsh takes his readers into the homes of the upper classes, in order to show how there is no propriety as such, no stability. The houses only exist in being transgressed, in having the limits of their boundaries exposed not by something foreign but instead by the other-within, by instances of difference without which the home cannot be defined in its propriety, and yet which it relies on for its definition, for its reflexive grounding and supposed safety and authority. Given that Atherton, Marjorie Linden and Lessingham belong to the upper classes, their homes should in principle figure by synecdoche that which is safe, reassuring and familiar. They are the domestic and private loci of hegemonic power and the ideological values of the status quo-or at least ideological consensus. However, the ruling classes of The Beetle do not behave in their London homes as a middle-class readership might expect of its leaders, of those who are looked to, to set the tone for home life in the capital.

Coming back though to the matter of the 'improper' use of mesmerism, we should note before going further that 'impropriety' is always already inscribed as other in the very concept of propriety; the displacement of this, the occlusion of the necessity of structural difference, is displaced conveniently on to the 'illegal-foreign'. In being foregrounded in this illicit manner, such uses aim at undermining any self-reflective certainties about the stability of identity, whether one is speaking of class-position, masculinity, femininity, national identity, and indeed a secure belief in one's own position as a subject of empire. In the hands of the 'degenerate' and 'Gothic' foreigner, capable of moving about the city “"[u]nseen, in the darkness and the night”' 
( $B$ 65), mesmerism is not merely a narrative device; it is also an effective tool for rewriting ideological assumptions and unquestioned cultural values, whilst 'translating' the streets of London into unpredictable locations for its inhabitants' potential abjection. As a means to unsettle identities and relations in the empire's capital, it proves efficacious as a narrative device in unleashing irrational and unconscious fears in London. Specifically, Marsh achieves this by providing the Beetle with a counter-narrative, and one, which, if taken seriously, may prove to have an undue influence on the susceptible reader. Marsh's aim then is to undermine conventional justifications of imperial or colonial activity through displaying transgressive, hitherto hidden practices on the part of an Englishman who is also a representative of political power. Specifically, the Beetle strikes at parliamentary power through the pursuit of the Liberal politician Paul Lessingham on the grounds of supposedly justifiable vengeance, by revealing activities on the part of Lessingham, not dissimilar from, and therefore analogous with, those of the Beetle in London. Mesmerism figures as a form of defilement, but of the psyche and not the external, material aspects of a culture.

From this, mesmerism is clearly readable as an act analogous with sexual penetration, an analogy borne out in both Dracula and The Beetle. There is also a threat through the ‘interpersonal intimacy’ of mesmerism to conventional cultural and psychic constructions of gender—men are described in novels such as Marsh's as being 'unmanned', while women are psychically, if not physically, violated. The Beetle's mesmeric force is also a colonizing one in effect, a furtive process, pursued undercover of night that 'conquers' the citizens of the capital. Furthermore, the specifically sexual threat of this foreign other taps into what Elaine Showalter has described as the fin de siècle's 'syphilophobia' (88), the anxiety and fear of widespread transmission of sexually transmitted disease. One example of such pathological cultural anxiety 
can be read in the long-fostered myth that British soldiers would bring sexual diseases with them returning from foreign campaigns, such as those in Egypt and the Sudan throughout the 1880s. It is not too much of a stretch perhaps to read the pervasive, insistent and often seemingly invisible movements of the Beetle throughout the night streets of London as the allegorical or symbolic inscription of the potentially unstoppable thread of a disease within the very heart of empire. Kelly Hurley places this assertion on firmer, more material ground: 'a paranoiac text like The Beetle serves to reflect and feed into British suspicion of and contempt for Egyptians during a period of heightened British military activity in Egypt'. Additionally for Hurley, 'it is precisely [the setting of London] which masks the British imperialist project informing and underlying the text' (127).

The greatest ostensible, perceived threat of the foreign other's application of mesmerism is then to any sense of national, cultural and personal self, of which the sexual and gendered aspects of identity were but the most vulnerable facets. There is though, we should remind ourselves, that other veiled reading, having to do with English domestic improprieties on the part of the upper classes, for which Marsh's story, and the Beetle, act as apparatuses of discovery. Between the analogies of sexual and psychic penetration and contamination, the constitution of Englishness is under attack, as is the grounds of its authority on the domestic front. Alison Winter remarks that there were 'two very strong reasons why mesmerism should have made Europeans uneasy: one was the problem of association between the races; the other was the more profound question of what coming under someone's influence meant in this context' (198-99). Allowing the foreign other control over the Englishman or Woman, as takes place in Marsh's novel, produces that imaginative reversal of colonial relations between master and servant, even as within the narrative Marsh produces the association of the "vulnerability of the mesmeric 
subject with colonial subservience', as we have already implied (Winter 199). To extend this a little further, the fear of the foreign other's presence in England in general and in the capital in particular manifests the externalized articulation of the fear of proximity, intimacy, contamination, and penetration that mesmeric invasion of the subject's psyche may be read as figuring. In addition, the threat of potential or imminent dangerous and intimate proximity can never be underestimated of course, when the other pursues its schemes at night.

The Egyptian Beetle is only ever encountered secreted away, largely unobserved, in an unassuming 'villa' in a West London suburb, its own cultural marginality doubled by the middleclass topographic margin of the villa. From here, it unnervingly intrudes or dispatches its agents to penetrate into the private houses of the English ruling classes. In a parallel structure it is found also working its hypnotic way into the minds of the English, in a series of what Roger Luckhurst calls trance-gothic encounters. One particularly disorientating aspect of Marsh's penetration of the city and its ruling classes arrives via the textual mapping of London, through the mesmerized agency of Holt, and subsequently through his narrative. While Holt offers little description of the streets, he does plot his route through districts and streets to the home of the politician Paul Lessingham:

The greater part of the route along which I was driven--I know no juster word-was one with which I had some sort of acquaintance. It led, at first, through what, I take it, was some part of Walham Green; then along the Lillie Road, through Brompton, across the Fulham Road, through the network of streets leading to Sloane Street, across Sloane Street into Lowndes Square. (B 70)

Despite the absence of recognizable landmarks or any detail concerning location, the street names provide the reader with very precise, mappable locations. What takes place in this 
process - and it is a process that is repeated throughout the novel - is that perception and mimetic representation (and with that specific identity) is occluded, as the city becomes reduced to topographical coordinates and denomination. Moreover, the telegraphy of the proper name may be said to heighten the phantasmic state for Holt, if not for the reader. There is to the list a sense of the disorientating rapidity experienced by Holt in his movement across London.

Let me make what might appear something of a digression at this moment concerning the suburban erasure of any of the characteristics that make the city districts distinctive from one another. Arguably, it is not only the velocity at which Holt is propelled, through the agency of the Beetle's supernatural powers, which forestalls any detailed representation of the London streets, their architecture or appearance. It is also, albeit implicitly, the endless — and to some, ineluctable - serial reiteration of rapid terraced expansion of domestic dwellings. This had begun, and had started its creep westward during the 1850s; it was, by the time of Marsh’s novel, 'radically, even aggressively suburban' (Porter 307), as is noted early on in the text. Roy Porter provides exhaustive detail on the suburban transformation of London in his comprehensive social history of the city, much of which of course takes place in conjunction with the spread of mass public transport and electricity. Arnold Bennett gives his readers an indication of just how enervating for some the London suburbs can be, when he writes in Riceyman Steps (published the year after The Waste Land) of Mrs Arb, that she 'abandoned...Fulham, where she had been dessicating for two years, and flew to Clerkenwell in an eager mood of adventure' (RSt 30). ${ }^{i}$ So lacking in apparent interest are the suburbs that almost anywhere is an improvement. Anonymity, placidity, ennui as the constituent elements of suburban London identity arise through repetition. So does another condition for the subject however, in his or her encounter with the unidentifiable, identicality: a kind of quasi-mesmeric disorientation brought about by incessant 
recurrence of architectural form These are the streets of the capital's suburbs to be found in the novels of H. G. Wells, W. Somerset Maugham, Arthur Machen, Amy Levy, and many others. Consider this passage, from Levy's 1889 novel, Reuben Sachs, which text will be discussed at greater length in Chapter Three:

The Walterton Road is a dreary thoroughfare, which, in respect of unloveliness, if not of length, leaves Harley Street, condemned of the poet, [Tennyson, of Wimpole Street, in In Memoriam 7.2] far behind.

It is lined on either side with little sordid gray houses, characterized by tall flights of steps and bow-windows, these latter having for frequent adornment cards proclaiming the practice of various humble occupations, from the letting of lodgings to the tuning of pianos. (RS 82-83)

Though a different district and rendered in more detail, Levy’s London suburb is essentially the same as those described fleetingly by Robert Holt. The quiet oppressiveness of the fin de siècle suburb is expressed as repeatedly in literature as it was to be found in the last two decades in the capital. Such numbing repetition may well account, I would contend in passing, for the relative lack of detailed description of London street scenes in many later novels of the nineteenth century staged in London, and not a few of the first decades of the twentieth.

As the city is remapped, so the novel in the last years of the century redefines its focus away from the City, as if to provide a mediation of its own readers' identities, and to make the adventures of London relevant to a suburban middle-class, whose world was becoming more parochial and circumscribed, in no small part from the sense, however fallacious, that the traditional centres of London and the City were too dangerous, too filled with adventure. Between the tedium of Levy and the abjection of Marsh, there is also the literature of smug self- 
interest (or at least, a parody of just such a condition). It is just the sense of self-interested insularity and complacency that George and Weedon Grossmith parody through the caricatured figure of Pooter, a city clerk, in the sharply satirical The Diary of a Nobody, which first appeared in Punch in 1888, and in volume form in 1892, just five years before Marsh's novel. I do not intend to spend too much time on this hilarious comedy, so necessary in its time to puncture the pretensions of the petty-bourgeoisie. We can learn an almost inordinate amount though from a few details.

Pooter lives on 'Brickfield Terrace' (11). The very name of the street is blatantly suggestive of the unending sameness, especially in that oxymoron of a brick field. The house is given a name, 'The Laurels', presumably this being the only way to distinguish one's house from all the others in the street. Aspects of the rented house are small and pleasant, unthreatening. There is a 'little front garden', a 'little side entrance', and a 'nice little back garden' (11). Mr Pooter goes to the expense of 5d for a 'capital little book' on gardening (22). 'Enlarged and tinted photographs' on the walls look very nice', especially when Mrs Pooter, Carrie as her husband's diminutive reminds us, adds silk bows to the corners of the frames (92). Pooter's mode of reference is very telling, for, apropos of nothing, ('By-the-by') he draws attention to the photographs for the sake of displaying the Pooter aesthetic sensibility. The Pooters have just one servant, except when they hold their first party seven months after moving in, when their son puts them to the — to Pooter Sr. - unnecessary expense of hiring a waiter for the 'half-dozen' of champagne' (91); and there is, as in this comment, a constant concern with value for money (the garden backing on to the railway tracks brings about a reduction of the rent by $£ 2 ; 11$ ). Though the couple suffer 'no inconvenience' over a crack in the garden wall, yet inside the house 'there is always something to be done' (11). The reader is then afforded a catalogue of 
domestic adventures: 'a tin-tack here, a Venetian blind to put straight, a fan to nail up, or part of a carpet to nail down'. Chintz covers are ordered to be made, 'for our drawing-room chairs and sofa to prevent the sun fading the green rep of the furniture' (21). The woman 'called in' to make the covers is recognized by Mr Pooter, proving reassuringly 'how small the world is' (21). The most distressing event in Mr Pooter's life is the unavailability of good sausages, accompanied by anxiety over a small investment (137). Faced with this, one wonders whether it might not be better to be abducted, if not by a supernatural creature then by aliens; and this in turn leads one to speculate on the reasons why H. G. Wells wrote The War of the Worlds.

However, to return to The Beetle and the more sensationalist horrors of the suburban location: Before his encounter with the creature, Holt is used initially in the novel to observe the rapid development of suburban housing in West London. Holt is of course Pooter's other, an unthinkable manifestation of the petty-bourgeois clerk, an abject anticipation of Forster's Leonard Bast. The point to be made is that alterity is produced by the city, by the mechanisms of a monstrous London far more terrifying to make its own workers invisible to their peers, than any merely imagined foreign creature. The novel's opening is one of the most truly startling scenes in urban literature, with its implicit ideological critique, and with the verbal and physical denial of shelter for someone who is both an inhabitant and product of the city. London is a grotesque nightmarish automaton, producing as its abject waste those whose energies it has employed, and which, in turn, it has rendered as surplus product. Thus Holt's appearance, homeless amongst the fast developing suburbs with their newly constructed or unfinished 'homes' for those not unlike Holt, is an uncomfortable image, to say the least.

Of the house in which Holt takes refuge in the first chapter, he remarks: 'It was one of those so-called villas which are springing up in multitudes all round London, and which are let at 
rentals of from twenty-five to forty pounds a year' (B 46). Such fleeting impression of suburban areas such as Hammersmith and West Kensington in the midst of rapid transformation is later supported by remarks of Marjorie Lindon (B 217) and those of Miss Louisa Coleman, who compares the new erections of 'high-class mansions' with those already in existence in 'Grosvenor Square-no shops or public houses, and none of your shanties' (B 271). Architectural reiteration, planned similarity and, with that, anonymity or at least the erasure of district-specific identity, is implied in the historical vision of suburban development encapsulated in Miss Coleman's remark. The singularity of identity dissolves—and this is what takes place in Holt's rapid transport across west London, cited above—even as London spreads like a mutating coral reef (to borrow a favoured metaphor for urban sprawl in the 1890s).

Monstrous, hallucinatory, disorientating — phantasmagorical London: the same everywhere and everywhere the same; which paradoxically, in dismantling identities, provides a focus for anxiety and fear through mechanisms of displacement and condensation, as if the city were some huge Freudian psyche, or alien replicating force. Thus, we come to see how, whether externally or internally, the borders of any identity or location are always permeable and always available for haunting in the uncanniest of ways imaginable. Moreover, this permeability is even more pronounced when perceived through the labyrinthine irrationality of London's topography and street organizations. Like a rhizomic body, the city is open to attack, infection, penetration, and infiltration from any direction at any time, but all the more so at night time, when most of The Beetle takes place.

III 
Typical of many late nineteenth-century novels and short stories, The Beetle explores what Kate Flint has described as 'the uncertain boundaries between fiction of the supernatural and that which dramatizes the workings of the inner mind' (252). However, in the case of Marsh's novel, the 'inner mind' is as much the national psyche of fin de siècle imperial Britain. Equally, this psychic space is rendered and projected for both its characters and its readers through the perception of a monstrous London, filled with night-time threats - London-phobia in the fin de siècle is the cultural equivalent of US cold war paranoia as encrypted in movies such as Invasion of the Bodysnatchers. Belonging to what Nicholas Daly calls the 'romance revival' of the fin de siècle (4-29), The Beetle exemplifies a form of popular narrative which seeks to accommodate the anxieties of late imperial English national identity, as already remarked. It does so by testing the virility of that identity through the arrival of some threat. Its being set in the Megalopolis of London only serves to exploit and intensify, as well as accommodate, such irrational fears, the difference being that it manifests the threats - for there are more than one — as being of the city, produced by it and belonging to it.

It is clear that Marsh's beetle-human hybrid provides a powerfully exemplary grotesque embodiment of late Victorian anxieties in many ways. Not the least part of this 'incorporation' is its encrypted, and therefore at least partially repressed, 'memory' — of colonial history in the nineteenth century generally and, in particular, the decade or so prior to the publication of The Beetle. The body is grotesque because it is unstable, excessive, ambiguously traced by so many fragments of identity. It bears 'the marks of the construction of femininity, "race” and sexuality' (Halberstam 252). However, the beetle-creature is readable as a disruptive figure. The Beetle gives face to everything that is unstable in late imperial culture. Other characters' reactions 
during and after their encounters with the creature serves to produce the novel — and therefore London — as a site onto which is mapped the cultural concerns of the period.

Why though it might be asked, does Marsh choose to make his creature Egyptian? What is there to be read in the relation between Englishness and Egyptian identity? While Dracula's popularity has been a constant throughout the twentieth century for the obvious reason that the vampire remains to this day a potent, mystified symbol of our fear of the other, Marsh's exploration of cultural anxiety concerning the occult archaic culture of Egypt may, today, be less immediately apparent. From one perspective, the post-Darwinian pseudo-theories of Havelock Ellis offer a substantial reason. Ellis claims that the 'true degenerative abnormalities $\ldots$ in the lowest human races' are found most often 'in Africa ... among the indigenous fellaheen, Berbers, and negroes of the Soudan' (70-71). Equally, socially and historically, there are other equally clear interests at stake.

As is well known, English and European, specifically French, interest in Egypt as other has a long history (since the Crusades at least). Such interest manifested itself through colonial, cultural and commercial activities. In 1798, Napoleon invaded Egypt in order to destroy British trade in the Middle East and Britain’s established trade routes through the area. As Edward Said avers, Napoleonic exploits in the Middle East accorded a privileged status to Egyptology (263) because Ancient Egypt offered, in its model of a dynastic civilization, a legitimation for Napoleon's own dynastic ambitions. In 1799, French soldiers discovered what has since become known as the Rosetta Stone (named after the village in which it was found), the deciphering of which eventually gave access to the decryption of the hieroglyphs found in temples, tombs, and pyramids. In 1802, the Rosetta Stone was removed to the British Museum in London, where Jean François Champollion eventually decoded its combination of hieroglyphs, demotic script and 
Greek in 1822. In 1801, the Ottomans, in alliance with the British, forced the withdrawal of Napoleon's troops, the British being able to re-establish commercial and colonial interest in Egypt and surrounding regions. While British cultural interest in Egypt and in all aspects of Egyptology developed throughout the century, the British strengthened their position in Egypt throughout the Victorian period.

With a century of close commercial, political and cultural involvement and investment must come sustained, if misread, perceptions of the foreign other. The Beetle channels and exploits a number of fears, anxieties and obsessions concerning different manifestations of the other in a narrative typical of much fiction of the time, one that mediated cultural anxiety. What gives all the more force to the irrational threat of the Beetle is that its foreign, non-European alterity is so intimately enfolded with its ancient and irrational nature, whereby Marsh mines what Robert Mighall describes as 'the major organizing figure of the Gothic', which is its 'imputation of anachronism as a source of disorder' (249). Extremity of cultural age, with its hint of the 'unnatural' prolongation of life, 'disorders' notions of life itself, especially when the sources of this 'life' are religious practices so at odds with the transcendent beliefs of late Victorian Christianity. Beyond its strategic topographical and practical economic value, if Egypt's exotic cultural appeal throughout the nineteenth century for the English lay in the remnants of its pre-Christian antiquity, then that very same archaic identity is also the source of its perceived threat. That antiquity suggestive of an empire and civilization, as well as a culture analogous with modern imperial and colonial identity is disruptive and disturbing because, while being similar in some regards, that resemblance nonetheless operates only through the disjunctive reminders of its also being other. 
For the archaism of Egyptian civilization is not simply figured as the survival of a single predatory and vengeful figure. This hybrid creature, symbol in Marsh's grotesque and phantasmal narrative of an entire culture, serves as an uncanny reminder that Empires, religions and dynasties do not last forever, but leave only the material reminders of their own mortality, haunting us because we see in them our own corporeal, cultural, and historical finitude. Thus, the figure of the beetle operates as a singular and disquieting example of the Freudian uncanny, in a number of ways. As is known, the uncanny is defined as that which causes feelings of horror and dread in the most familiar places, the places where one should feel the safest. In The Beetle, this is simultaneously London, the centre and capital of empire, and the houses of the ruling classes in that city. Also, the figure of the Beetle produces ontological and gender uncertainty; it doubles, divides and exchanges a series of selves, while its returns and appearances may be read as 'the constant recurrence of the same thing' (Freud 210).

In its doubleness and as representative of a long-vanished culture the beetle's uncanny resonance is most discomforting. The creature is suggestive of both an 'assurance of immortality' and 'the uncanny harbinger of death' (Freud 210). ${ }^{\text {ii }}$ More than this, the beetle is available for a reading of it as trope for that which is neither dead nor alive, but which returns and hovers between either condition. In this, it has the potential for 'awakening uncanny feelings ... created when there is intellectual uncertainty whether an object is alive or not' (Freud 208). Furthermore, Freud argues, 'many people experience the feeling in the highest degree in relation ... to the return of the dead, and to spirits and ghosts' (218). From this, Freud finds it hardly surprising that in modern cities spiritualist shows and related phantasmagorical entertainments abound, promising to bring back the dead, and this is advertised in Marsh's text through the recourse to mesmerism. In our fascination with such processes as telepathy, mesmerism and 
spiritualism, Freud sees in modern urban humanity the vestiges of a collective 'primitive' fear (219). In doing so, he acknowledges that which is other and repressed within us, something archaic and intrinsic to identity rather than being externally other.

This is of course an important aspect of The Beetle and is unfolded through the Beetle's synecdochic function of standing in for the archaism of Egypt, which, I would contend, offers to impose upon the English of the novel generally and through the 'contamination' of London specifically an unpleasant recognition concerning the colonial and imperial mission. To read The Beetle against the grain of its fin de siècle fear of the other, where barbarism is located in Egypt and civilization in London, it has to be argued that the human-scarab hybrid pursues the politician Paul Lessingham, less from some irrational and barbaric Oriental blood-lust, than out of a sense of injustice for the 'barbaric' English defilement of ancient Egypt's sacred locations, where tomb and temple have become defaced as a result of colonial and imperial intrusion, and by colonialism's by-product, tourism. Thus, from such a counter-reading, it can be said that the other, the not-self that returns, arrives not from another location, but from within one's own identity, as a necessary yet repressed mirror of the self that is so much the concern of late imperial English literature.

IV

From all that has been said so far, it is clear that The Beetle is a novel materially engaged in an imaginative encryption of historical, cultural and political fears emanating from and mediating particular aspects of the English psyche at the end of the nineteenth century. The Beetle is, moreover, exemplary of a world without a stable centre. This is a world where identity is never 
identical with itself, where all that can be said, of the Beetle for example, that it/he/she is 'the same, yet not the same', as Robert Holt has it ( $B$ 60). In this it certainly offers one analogical model for perceiving not only London, but, admittedly much more indirectly, the perception of London at the fin de Siècle, in a world in which the figure of Babylon was so overused as denomination tending towards representation as to have any significance erased from it. Additionally, The Beetle - and the Beetle-figure sites for the focus of anxiety in an almost perpetually night-time London, capital of nation and empire, in which the very possibility of agency, whether individually or collectively on the part of the English, is called into question.

The London the reader encounters in Marsh's novel abounds with elements recognizable from many other fin de siècle mysteries, a number of which we have already addressed. It is an inhospitable, largely nocturnal city, where darkness and adverse weather conditions, make possible, while simultaneously hiding, criminal and transgressive behaviour. However, Marsh’s London is not purely this. For the novel begins with representations of the city that, while partaking of tropes recognizably similar to those that construct the images of the city in the works of authors such as Conan Doyle, R. L. Stevenson, Bram Stoker, and Oscar Wilde, belong to more realist and naturalist fictions, such as those, for example, of Walter Besant, George Gissing or George Moore, or Arthur Morrison. In presenting the narration of the tramp Robert Holt, homeless and wandering the streets of West London suburbs in search of a night's accommodation in the Casual Ward, Marsh offers the reader a glimpse, however fleetingly, into the wretched existence of the capital's poorest inhabitants, the conditions of whom are a byproduct of the city. What is all the more startling about the particular image of Holt is that he is not from the working classes but had been a clerk until his dismissal. Furthermore, Marsh stages the initial scene not in the East End of London, as is commonly the stereotypical setting for late 
Victorian Gothic, but in the upper and, as we have remarked, largely middle-class districts of West London, from Kensington to Fulham. In small, subtle ways therefore, The Beetle is available as staging an alternative, possibly estranging vision of the city for its readers that is unveiled from the contest between the tropes of fin de siècle sensation and those of the text of social realism, while displacing narrative events belonging to both genres from their already clichéd sites in the 1880s and 1890s, East London.

Admittedly, Marsh's acts of what may be described as cultural and literary revision are not sustained in any significant way. However, what is effected in this manner is a disruption in both the literary codes of urban representation and the narratives that are informed by such codes. The city's identity is made to tremble, as are its ontologies and epistemologies of representation. Not only this, but it is not impossible that, in such gestures, The Beetle invites one to reflect on the identity of literary models beyond their diegetic codes or mimetic commonplaces. Events occur in places that they should not, borderlines are crossed both in the imagined topography of the city and in the modalities of genre. London in this particular guise is therefore the 'same, yet not the same', to borrow Holt's words once more. Identities are mixed and thus confounded. What, it might be asked, makes this possible, in the first place? Arguably, London itself, already perceived by countless cultural commentators and novelists as monstrous, labyrinthine, indefinable and irreducible to a single identity, excessive beyond hybridity, amorphous, and endlessly heterogeneous, heteromorphous, and heterographic.

Apprehending such conditions as being of the very 'nature' of the city, we might come to understand how the Beetle is, after a fashion, the most typical London inhabitant; its is the most appropriate identity within a city which, like itself, cannot be fixed as a single identity. To risk hyperbole, it may be averred that not falling under any single category of identity or 
identification, not only is the Beetle more a 'Londoner' than any of the other characters, it is the only Londoner. Unable to belong or to remain as itself, within itself, and therefore always subject to (of) translation, it is in a strange way homeless, and therefore uncanny. And it is just this condition of being-homeless, being-uncanny, that marks the Beetle, even as it marks the text that bears its name, as the countersignature to London, that other denomination for which there is no referent, no thing without difference. The city thus dictates the writing of the Beetle, even as that creature returns to the city the archaic traces and traits of excessive, abyssal and improper identification that analogously re-mark London. In this abyssal relation without relation that I am mapping here, at once hetero-topic and hetero-tropic, a certain textual drift is readable as underway from the very beginning of the novel. Such textual drift 'contaminates' the very writing of The Beetle itself. For the novel is without proper form. Not formless, but improperly formed, deformed and disfigured within and across itself, The Beetle has no single identity, no single narrative presentation. From its inauguration with its mixing of genres; through its multiple narrative relays between narrators and within narrators; from parody of 'New Woman' fiction to pastiche of detective genre, the excess beyond identity and the simultaneous resistance to any simple or single identity of The Beetle announces its own 'impure' affiliations, its relation without relation, both to the creature to which the title refers and to the city that makes possible and authors all such narratives.

To return to London and its representation: in making Holt homeless, in expelling him from any 'home', whether by home one refers to a dwelling or an identity, the city authorizes the narrative that figures the city. Thus, the experience of the city returns to the reader as one of estranging abjection and unhomeliness. Nothing is familiar in the ephemeral images of the city's 
material conditions, either in those images of architecture or topography, afforded the reader in Holt's narrative. Take Holt’s following commentary:

The rain was like a mist, and was not only drenching me to the skin, but it was rendering it difficult to see more than a little distance in any direction. The neighbourhood was badly lighted. It was one in which I was a stranger, I had come to Hammersmith as a last resource. (B 45)

First speed and now the atmospheric limitation as well as the lack of illumination imposed on sight estrange the subject from any possible familiarity with place. Homeless and a stranger, Holt's experience of the location re-enforces a sense of that any object by which the self can find its orientation or grounding is spectacularly absent. Such effect—or perhaps we should say such affect — is all the more pronounced by the physical limits on vision, on which Holt remarks slightly further on in the same passage:

Retreating from the inhospitable portal of the casual ward, I had taken the first turning to the left, - and, at the moment, had been glad to take it. In the darkness and the rain, the locality which I was entering appeared unfinished. I seemed to be leaving civilisation behind me. The path was unpaved; the road rough and uneven, as if it had never been properly made. Houses were few and far between. Those which I did encounter, seemed, in the imperfect light, amid the general desolation, to be cottages which were crumbling to decay.

Exactly where I was I could not tell. I had a faint notion that, if I only kept on long enough, I should strike some part of Walham Green. How long I should have to keep on I could only guess. Not a creature seemed to be about of whom I could make inquiries. It was as if I was in a land of desolation. (B 45) 
What is to be observed especially in both passages is the sense of defamiliarization of the self in relation to location. In the second of the two passages, Holt begins by acknowledging specific directions. His memory offers particular bearings. Yet immediately, as soon as a direction is chosen, sight has imposed on it limitation and restriction due to the darkness and rain, and Robert Hold observes immediately the incomplete condition of the location in which he finds himself. If we accept Heidegger's suggestion that dwelling is the condition brought about by the relation between being and space, and, from there to the relation between space and the desired grounding that location affords (B 155), then clearly for Holt, his sense of being is violated—by the limits of orientation, the limit of vision, the incomplete structural condition of location, and the apparent sense of no longer being, as he puts it, in civilisation.

That this is not merely Holt's experience alone is undeniable. Rather it is a shared phenomenal encounter, wherein is apprehended the condition of the uncanniness of being, of the articulation of a kind of Dasein in the city, may be acknowledged through the experience of another character, Marjorie Lindon's. Although there is not the space to go into the comparison in any detail, the follow passage will allow the reader to consider what is shared between the two characters. Marjorie's description of the experience of place refers to the same location as Holt had found himself in, and yet, despite Marjorie’s encounter with place occurring in the daytime, her experience is not at all dissimilar. Here is the account in her own words, taken from her narrative:

The road he had chosen seemed to lead to nothing and nowhere. We had not gone many yards from the workhouse gates before we were confronted by something like chaos. In front and on either side of us were large spaces of waste land. At some more or less remote period attempts appeared to have been made at brick- 
making, - there were untidy stacks of bilious-looking bricks in evidence. Here and there enormous weather-stained boards announced that 'This Desirable Land was to be Let for Building Purposes.' The road itself was unfinished. There was no pavement, and we had the bare uneven ground for sidewalk. It seemed, so far as I could judge, to lose itself in space, and to be swallowed up by the wilderness of 'Desirable Land' which lay beyond. In the near distance there were houses enough, and to spare--of a kind. But they were in other roads. In the one in which we actually were, on the right, at the end, there was a row of unfurnished carcases, but only two buildings which were in anything like a fit state for occupation. One stood on either side, not facing each other,- - there was a distance between them of perhaps fifty yards. The sight of them had a more exciting effect on Mr Holt than it had on me. (B 217)

Marjorie's is a representation that emphasises yet again incompletion, an absence of any proper identity and, with that an accompanying indeterminacy; chaos and disorder, decay before completion - these are all that are to be read. The tropes of urban representation trope themselves and imprint themselves on the language of the city's different subjects. What Marjorie's observations do seem to support therefore is that, while Holt's mental condition is not completely stable, how he sees the city is not peculiar to him. It is, instead, the very condition of certain aspects of London, which aspects produce particular effects in the rhetoric of urban representation at the fin de siècle. London alienates and makes abject, doing so through the inscription of its spectral imprimatur. That language attests to the otherness of the city is fully in evidence here. What is seen and responded to quickly reach exhaustion in verbal representation. This is neither chaos nor the absence of chaos, only 'something like' that state, a liminal approximation, the condition being unapproachable except by vague simile. The road goes nowhere, and leads to nothing, Marjorie's second provisional definition, following chaos, of a 
'waste land', inadvertently anticipating T. S. Eliot's title in the separation of the two terms. What can be expressed comes about in what might be readable as a pastiche of archaeological or ethnographic discourse, with its references to anonymous activity at 'more or less remote periods'. So unavailable is any appropriate language indeed that Marjorie perhaps registers her own disconcerting unease in her quasi-anthropomorphic representation of bricks as 'biliouslooking'. This strange animal apprehension is further taken up in the image of buildings as carcasses. Everywhere in the passage, Marjorie admits to her own phenomenological perplexity. While the site, and, to risk the pun, the sight of the site, has a 'more exciting effect' on Holt than on Marjorie, the signs are there inescapably that Marjorie is also affected in her disorientation, and hence in her reading of the location.

This abject reflection on being is further disoriented by the doubly anachronistic experience of location. For, on the one hand the area appears as if it stood outside civilization, and thus had returned as some atavistic hallucination, while, on the other hand, the site is suggestive of some post-apocalyptic moment. Desolation and decay — watchwords for the fin de siècle — signify this alternative temporal moment. Thus, we read the city through Holt as the experience of past and future, but not as some present. We would also do well to recall at this juncture that Holt's experience is a result of the encounter with the city, and therefore his perception, however disorientated, estranging, and hallucinatory, is not the result of the Beetle's mesmeric powers. For the tramp's mise en scène threatens to collapse into a state of mise en abyme. It is of course the effect, at least in part, both of atmospheric conditions and the entry into an area the building of which is not yet finished; furthermore though, these are undeniably the effects of homeless, exhaustion, and lack of nutrition. All of these are caused by the city, not by some monstrous or alien other. Unless one is forced to admit that monstrous alien other just is 
London. In Holt's narrative we read what Julia Kristeva has called, apropos of Céline, 'a narrative of suffering and horror' (140), ${ }^{\mathrm{iii}}$ which in Holt's case is produced by London. If the subject has no proper place, no appropriate location in which to ground himself, then 'suffering' is articulated 'as the place of the subject. Where it emerges, where it is differentiated from chaos', in this case the chaos that is the city-in-ruins, not as a result of decay but because London is undergoing the experience of rapid, protean and excessive transformation. And the result is that through his perceptions, his bearing witness to such violent upheaval, Holt the Londoner affirms through observation of unbearable incompletion that sense of 'Being' that Kristeva describes as 'ill-being'.

The sickness of Being imposed by London (and which, perhaps, may be ascribed as one factor in any provisional identity for the city also) comes to a pitch when Holt says 'I looked about me, in a kind of frenzy' (B 46). There can be no doubt that it is as a result of urban social forces that have produced this psychic disorder in Holt, and it is only the sudden consciousness of a house — of a supposedly familiar, and therefore safe location — that saves this abject figure, later described by Sydney Atherton as a ‘City quilldriver out of a shop’ (B 255). Atherton's casual phrase offers a passing but nonetheless telling reminder of the direct link between the City and Holt's state of being. This being the case, arguably the Beetle's mesmeric power only serves to reveal the full extent of Holt's condition. Indeed, while mesmerism may account for much, in a later statement concerning his trance-induced propulsion through London, Robert Holt observes the following:

All the way I never met a soul. I have since wondered whether in that respect my experience was not a normal one; whether it might not have happened to any. If so, there are streets in London, long lines of streets, which, at a certain period of 
the night, in a certain sort of weather--probably the weather had something to do with it--are clean deserted; in which there is neither foot- passenger nor vehicle, —not even a policeman.

$[\ldots]$

Who goes that way goes some distance, and goes through some important thoroughfares; yet not a creature did I see, nor, I imagine, was there a creature who saw me. As I crossed Sloane Street, I fancied that I heard the distant rumbling of a vehicle along the Knightsbridge Road, but that was the only sound I heard. (B 70)

That Holt's testimony to desertion raises the spectre of the undecidable simply by its being articulated presents the reader with the impression that London, at a certain period, in a certain sort of weather, may not have, in fact, the 'power' to produce uncanny effects. Look at the language Holt employs: he speaks of wondering retrospectively, attesting to the way in which his experience remains to haunt his mind. He acknowledges the abnormality of the events. His speculation that the experience might have occurred for others speaks to that sense that the effect is produced by London. The first and second passages are structured around undecidable reflections and negations, as well as corollary images of absence. And Holt speaks of imagining and fancying. What is most uncanny about London in this representation is not the absence of life, but that of sound. Is it in fact the city then causing this condition and the registration of effects on Holt? How can we know? How do we tell?

The answers to these questions are, inevitably enough, that we cannot. However, in this aporetic moment, what we might glimpse is precisely the possibility that to apprehend the city at all is to recognize and so bear witness to that uncanny encounter as the unpredictable event which London makes possible. Its secret is there, but encrypted in its very being such hieroglyphic inscription remains untranslatable. To put this somewhat differently: for the 
perceiving subject to experience of the city in such extreme moments is to encounter, and subsequently recognize, 'the existence of an Other...analogous to the I which is the subject of perception’ (Augé 1999, 96). The mirror phase is reversed as Marc Augé, just cited, goes on to suggest; and one apprehends that the 'Other is an I' $(1999,96)$. In the example offered by Richard Marsh, this apprehension is truly terrifying inasmuch as what the other ${ }^{\text {iv }}$ makes known is that there is no stable ground to being, to identity, or therefore to any narrative by which one claims to orient oneself. Beyond any immediate social or economic abjection (even though these are admittedly not insignificant), London, a figure without proper figure for absolute alterity, gives one to know the groundlessness of one's own being. If there is no sustained representation of London in The Beetle but only the dim, amorphous, uncanny perception of a 'there' that is never totalizable as a 'there', this is perhaps because The Beetle is readable as an endless reminder that alterity is unrepresentable as such, that it has no finite form. This is so whether one focuses on the momentary passing references to the city as a topographical surface reduced to a few district and street names, or whether one considers the structure of the novel or the 'liminal man-woman-goddess-beetle-Thing' to which the title signals, and yet which has no identity properly speaking.

In this light, the extremity of Holt's condition is available to us because of his understanding fully the encounter with the other before he ever encounters the Beetle. The Beetle merely serves as some provisionally determinable threat against which the English can gather and offer themselves the illusion that identity can be stabilized once the other is destroyed. The irony is of course is that in the aftermath of the train wreck at Luton, no signs can be found that the Beetle is destroyed. It has disappeared as if it were merely a phantasm, the sign of some cultural psychosis, a displaced metaphor for all that London exacts as capital city and 'centre', 
so-called of empire. Whatever assurance of identity there may be found is only temporary in The Beetle and always ambiguous at best. We may notice this when Augustus Champnell observes of St Pancras station that, though it is in darkness and deserted (the absence of life here seems to point to a condition of the uncanny city once again, rather than being locatable as a symptom of Holt'), ‘[a]n occasional light seemed to make the darkness still more visible' (B 311). London, it may be argued, is the manifestation of 'darkness visible'.

$\mathrm{V}$

The purpose of any detective is to answer questions, to provide solution and resolution, and to enact discovery and, where necessary, recovery. The hired sleuth is therefore the very agent of urban romance. The late-Victorian or Edwardian confidential agent is also meant to serve in literature as prosopopoeic manifestation of a force, the principal purpose of which is to assuage the anxieties and fears of the culture at large: 'Detective literature deals with disturbance and destabilization as much as crime per se.... Detective literature ... confronted Edwardian issues such as gender redefinition, capitalism, cosmopolitanism, social class, international diplomacy, race deterioration and imperial policy' (Kestner 2000, 7). A number of these issues are already at stake in The Beetle and it is Augustus Champnell, the detective whose narrative concludes The Beetle, who might present the promise of bringing matters to a conclusion. Yet, this is doubtful. For Champnell's final remarks admit to the undecidability that is announced everywhere in the disturbing signs that serve in the presentation of Late Victorian London. Through Champnell, it is revealed that the tramp Holt's narrative, presented first in the novel is found to be a composite, not his own first-person report but rather compiled instead 'from the statements which Holt made 
to Atherton, and to Miss Lindon'. The detective thus presents the reader with the hitherto hidden textual basis on which the narration of events comes to be constructed. Several writings generate further acts of writing, enmeshing one in a textual web.

Furthermore, while Champnell begins Book IV with an assertive statement of fact — 'On the afternoon of Friday, June 2, 18_' ( $B$ 235) - the purpose of which is to suggest precision, attention to detail and reassuring certainty, he concludes what he calls 'the Mystery of the Beetle' with the assertion: 'I do not propose to pronounce a confident opinion. Atherton and I have talked it over many and many a time, and at the end we have got no "forrader"”.

So far as I am personally concerned, experience has taught me that there are indeed more things in heaven and earth than are dreamed of in our philosophy, and I am quite prepared to believe that the so-called Beetle, which others saw, but I never, was-or is, for it cannot be certainly shown that the Thing is not still existing - a creature born neither of God nor man. (B 322)

These remarkable statements, which are also the final words of Marsh's novel, oscillate wildly. They shuttle between recourse to fragile faith and subjective experience; they veer between the suspensive modality of belief — what if? asks Champnell — and the absence of empirical data. No amount of discussion can resolve these issues. The confidential agent and the scientist, representatives of the ruling class are forced to confront, thereby experiencing the aporia with which each man is confronted, that philosophical impossibility or undecidability leading in this narrative not to closure but to an abyssal impasse. London leaves one without passage, and from that only the confession of doubt. Such confrontation and experience is unsettling, causing the late-imperial English mind to reflect on the absolute limit of its inquiry and the impossibility of reaching a solution. The other renders the English helpless, impotent. Invoking Hamlet's 
attestation of the limits of the imaginative faculty, the detective admits to the boundaries not only of the knowable but also of what language may express or serve to represent. This is hardly reassuring coming from a representative of the modern science of forensics, whose primary purpose is to interpret the evidence in the name of the Law. It is to be noticed also that the creature is only provisionally named, while, chillingly, there is the implication that it can always return again, and again. In addition, there is that final comment, which registers a radical undecidability concerning the creature, and with that, the failures of analysis, whether grounded in empiricism, forensics, or ontology.

All the more disturbing for the reader perhaps is the fact that the failure of detection and determination on which the Englishman relies — on which, I would argue, national identity is initially and ultimately reliant — is not peculiar either to Champnell's or to Atherton's own abilities or lack thereof. We may begin to read this, I believe, as a more general condition of the English experience of the foreign other. This is interpretable in the fragmentary and reiterated use of negation throughout the final chapter. Years, we are told, have passed, or else Champnell 'should not have felt justified' in recounting the mystery of the Beetle (B 319). The detective 'declines' to specify the number of years (B 319). Marjorie Lindon's recovery was 'not merely an affair of weeks or months' (B 319). Paul Lessingham is not Paul Lessingham; or rather, this is the fictional name given to protect the real public figure behind it and whom it is intended to protect ( $B$ 319). Nothing has ever been said, Champnell assures us, to Marjorie about the catastrophic events she underwent at the hands —or should that be pincers—of the Beetle, while 'she herself has never alluded to it' ( $B$ 319). Curiously, Champnell is insistent on Marjorie's 'mute', traumatized condition with regard to the experience. He says twice more that she cannot speak of it (B 321, 322), though he does insist on her strange iterable compulsion to tell in 
writing — 'she told, and re-told, and re-told again' (B 322) — of her love and ordeal. Champnell also points out that Marjorie may have no memory of what happened and so, 'what actually transpired will never, in all human probability, be certainly known' (B 320). Neither will the fate of the Beetle ever be found out: 'to this hour these things are puzzles' (B 320). Paul Lessingham, the reader is informed, cannot bring himself to speak of beetles.

Finally, beyond the immediate details of this narrative, Champnell is compelled to narrate a tale concerning the destruction of a remote location, 'some curious subterranean building $\ldots$ the den of demons described by Paul Lessingham', in the Egyptian desert (B 320-21). Following an explosion, witnesses discover the remains of bodies, which, while neither men nor women, appear, it is alleged—-though without 'scientific examination', (and thereby open to disbelief and speculation)— to be 'of creatures of some monstrous growth' (B 320). Champnell's final narrative is in ruins itself, in a writerly performative replication of the 'den of demons'. The detective's account is nothing more than so many negative fragments, the negating force of which is cumulative in its effect on the reader as narrative description slides irreversibly into a performative speech act, so that the absence of knowledge spreads like a virus everywhere throughout the narrative, becoming an inextricable part of it. Even the cause of the death of Robert Holt could 'never certainly [be] shown' (B 321). The reader is left, at the conclusion of The Beetle, confronted by the signs of undecidability everywhere. Unlike Stoker's Dracula, Marsh's avenging creature leaves no signs that it has been conclusively, finally destroyed. Not all the forces of modernity, deployed in concerted and co-coordinated fashion, can rid the Empire of this 'creature born neither of God nor man', to call up the most haunting line of the text, its very last, in which negation opens, once more, onto an abyssal undecidability, all ontology rejected in the face of this radical other. 
Champnell's final words expose the futility of asking the instituting ontological question, 'what is ... ?' so that we are forced to admit that the book does not so much conclude as it confronts us with just this uncanny encounter with the aporetic. The text confronts us with irresolvable contradictions. Nothing can be said for sure, except that one can only admit the impossibility of saying anything other than to bear witness to an undecidable narrative event, which nevertheless calls for some response. In this, Richard Marsh’s novel is ultimately, like the Beetle, monstrous, a figure of catachresis, having no proper identity as such, being resistant to any single determination. Recognizing this, and given also the multiple ways in which the Beetle (and The Beetle) are readable as being signed and countersigned by many of the dominant anxieties of late Victorian culture, it might be necessary to understand the Beetle in a manner that departs from a literal apprehension of the creature's existence within the logic of the narrative. We should not read this figure as a supernatural creature, or indeed any form of being that we are expected to accept as more or less real. Instead, it is more productive, if more difficult, to approach it as an effect of some hieroglyphic writing; to see it as a trace irreducible to any particular meaning, and yet one which causes a proliferation of interpretation. In order to accept this, one would have to recognize that it is important that one suspends one's conventional reading habit — 'the naïve opening that once linked the text to its thing, referent or reality' (Derrida 1981, 43) — of perceiving an implied empirical object or metaphysical concept beyond the words on the page.

Another way to put this is to propose the following: that we resist treating the Beetle as a character, in any conventional sense or habit of reading. We should not give in to the temptation of perceiving this figure as an anthropomorphized embodiment of attitudes, rhetorical figures and descriptive language, beliefs and other systems of thought, gathered together and animated 
by the work of the proper name. Rather, we might attempt to decipher it in that other sense of character. We might wish to read it as a mark, inscription or engraving, a graphic symbol if you will, a form or system of writing; or a cipher the purpose of which is to encrypt and therefore make secret communication not about some other culture but about the other of our own cultures and identities. It is impossible, of course, to abandon altogether the phantasmic 'reality' that we, as readers, conjure whenever we read. It is though nonetheless necessary, I would contend, that we attempt to put the breaks on this process as far as possible with regard to the example of the Beetle.

I argue this only because there is such an hysterical rush in the novel, in which the unwary reader can be swept away in the cultural and ideological condemnation of the other given monstrous form. I am not suggesting that we humanize the Beetle —-the novel already engages in just enough anthropomorphization in order to make the creature appear even more monstrousin some simplistic dialectical opposition to the hegemonic colonial discourse already exposed. Rather, we should assume a reading habit at once cautious and suspicious of anything that would impose itself on us as logical, inevitable, or - scariest of all — common sense. Treating the Beetle as if it were only a 'real' monster would be to succumb to such common sense. If therefore we cannot help reading the Beetle as an organism, it has to be comprehended as an organism that, as I have already argued, resolutely resists any final commentary aimed at a firm identification. In coming to terms with this paradox, while holding out the possibility that one can do justice to the Egyptian other in its own terms, it might be necessary, in conclusion, 'to consider that organism as a hieroglyphic text' (Derrida 1986, xxviii). In this, it has to be said that far from being some merely externalized and abject other the Beetle is, if not the figure par excellence, then at the very least what I have called a countersignature for London itself. The 
very writing of this hetero-graph charges us to turn our gaze back on the monstrous city at the close of the nineteenth century. It demands that we turn our attention to that for which we have no adequate language, though it remains nevertheless our invention. As countersignature, it bespeaks a city, in the face of breakdown, the desire for annihilation, amnesia and epistemological crisis, 'resistant to the cognitive regimen of history' (Luckhurst 2002, 530), or indeed any other mode of determinable perception or ordering. As countersignature to the city, the Beetle is both 'gothic fragment' and ghostly revenant. It serves in presenting the city through the limits of its inhabitants to read it, and the breakdown of both their readings and themselves to varying degrees. The inhabitants of London we encounter are unable to elaborate 'the contexts for that specific topography of this London Gothic’ and this modern-Gothic London’. The Beetle — and The Beetle - thus punctuate and so contribute to London's aesthetic of resistance, as Roger Luckhurst has it of the purpose of finding, reading, and inventing the gothic fragment (Luckhurst 2002, 533). The 'violence of reading the ghost' (Luckhurst 2002, 542) in this manner therefore speaks to that which Paul Lessingham, Marjorie Lindon, Sidney Atherton, Robert Holt, and Augustus Champnell are unable to articulate: the politics of a London at the end of the nineteenth century and the 'demand of its specific symptomatology and its specific locale[s]' (Luckhurst 2002, 542). In this, the haunting force of the Beetle is not as some archaic 'find', the result of a colonial-archeological 'adventure' concerned with the origins of civilizations and knowledge'. It is rather a violent phantom inscription attesting to repressed, traumatic memories of the City's identity, awaiting recovery from within the city itself.

Notes 
${ }^{\text {i }}$ Although, in distinction to this, see Bennett's hallucinatory representations of the Upper Richmond Road in Buried Alive, discussed in the second part of Writing London.

${ }^{\text {ii }}$ Interestingly, Freud develops the notion of doubling in relation to death around the example of 'the Ancient Egyptians'.

iii All further quotations in this paragraph are taken from the same passage unless otherwise indicated.

iv While with his use of big ' $\mathrm{O}$ ' otherness and the reference to the mirror stage, Augé is drawing on a Lacanian paradigm, which in this instance I obviously support, I have kept the lower case for my own spelling of other so as to indicate a sense of alterity more generally epistemological than specifically psychoanalytic. 